\title{
Uma equação integral para modelagem elétrica 3D
}

\author{
Sérgio Cavalcante Guerreiro* - Aposentado/IFUFBA
}

Copyright 2018, SBGf - Sociedade Brasileira de Geofísica

Este texto foi preparado para a apresentação no VIII Simpósio Brasileiro de Geofísica, Salinópolis, 18 a 20 de setembro de 2018. Seu conteúdo foi revisado pelo Comitê Técnico do VIII SimBGt, mas não necessariamente representa a opinião da SBGf ou de seus associados. É proibida a reprodução total ou parcial deste material para propósitos comerciais sem prévia autorização da SBGf.

\section{Resumo}

Uma equação integral é introduzida como alternativa à equação de Laplace para modelagem elétrica 3D. É uma equação para as cargas elétricas de superfície depositadas, nas interfaces de regiões do subsolo com diferentes valores de resistividade, para ajustar as condições de contorno. A solução da equação é obtida através da série de Neumann, que pode ser implementada em notebooks. Conhecida a distribuição de cargas, potencial, campo elétrico e campo magnético, podem ser calculados em qualquer ponto do espaço

\section{Introdução}

O método de eletrorresistividade é baseado no conceito de resistividade aparente, que é o valor da resistividade de um subsolo homogêneo que desse a mesma diferença de potencial medida no campo. As curvas de resistividade aparente são obtidas deslocando-se 0 arranjo inteiro de eletrodos, e calculando a resistividade em cada posição. É claro que essas curvas não são funções físicas, pois cada valor corresponde a uma situação física diferente da anterior. Elas não podem ser interpretadas a partir da relação de causa-efeito, como se faz com potencial, ou campo elétrico, para um dado arranjo de cargas.

Neste trabalho, duas coisas são apresentadas: uma equação integral para a densidade superficial de cargas elétricas localizadas nas interfaces de regiões com valores diferentes de resistividade, e a proposta de que se faça a interpretação a partir de funções físicas, como potencial e campo elétrico. O conhecimento da distribuição de cargas permite o cálculo dessas funções, e também permite o cálculo do campo magnético produzido pelas correntes. A interpretação casada de potencial, campo elétrico e campo magnético, dará muito mais segurança na interpretação

\section{Metodologia}

\section{A equação integral}

A equação integral é construída a partir da expressão do campo elétrico, válida em qualquer ponto do espaço, composta pela soma do campo das fontes, localizadas nos eletrodos, e do campo das cargas de superfície, localizadas nas interfaces. Essa última contribuição é uma integral de superfície. Em seguida aplica-se a expressão geral do campo a pontos próximos às superfícies, e faz-se o produto escalar entre o campo elétrico e a normal local à superfície. Como essa expressão é singular no ponto de observação, um pequeno elemento de superfície é removida da integral, tornando-a não-singular. O valor local é obtido pela lei de Gauss. Aplicando as condições de contorno para as componentes do campo e a componente normal da corrente elétrica, obtém-se a equação integral

$\sigma(\mathbf{r})=2 \epsilon\left(\frac{\rho_{+}-\rho_{-}}{\rho_{+}+\rho_{-}}\right)\left[\frac{1}{4 \pi \epsilon} \int_{S^{\prime}} \sigma\left(\mathbf{r}^{\prime}\right) \frac{\mathbf{r}-\mathbf{r}^{\prime}}{\left|\mathbf{r}-\mathbf{r}^{\prime}\right|^{3}} \cdot \mathbf{n}(\mathbf{r}) d S^{\prime}+E_{f, n}(\mathbf{r})\right]$

onde $\varepsilon$ é a permissividade elétrica, $\sigma$ é a densidade superficial de cargas, $\rho$ é a resistividade elétrica e $E_{f, n}$ é a componente normal do campo das fontes; $\mathbf{r}$ é o ponto de observação, r' é o ponto de contribuição e $S^{\prime}$ é a superfície de integração. O índice + indica o lado da superfície para o qual a normal aponta, enquanto o índice - indica o outro lado da superfície.

\section{A solução da equação}

A solução da equação é realizada pela série de Neumann, que é obtida pela inserção da expressão da densidade de cargas, iterativamente, dentro de si mesma. Essa série converge e é a solução da equação.

Numericamente, a solução é obtida substituindo-se a integral por uma soma finita de contribuições de elementos de superfície planos, que cobrem todo o conjunto de superfícies do modelo. Note-se que essa soma não inclui o elemento localizado no ponto de observação, cuja contribuição já foi incluída na dedução da equação.

\section{Resultados}

As figuras abaixo mostram a função potencial e a componente horizontal do campo elétrico na direção da linha de eletrodos, para o modelo de um bloco imerso em um subsolo homogêneo. Nessas figuras o adjetivo secundário significa a contribuição das cargas de superfície, que se obtém subtraindo a contribuição das fontes do valor total medido.

Nessa teoria, os eletrodos de corrente permanecem fixos; na medida do potencial um dos eletrodos é mantido fixo no centro do arranjo de eletrodos, e o outro é movido. $\mathrm{Na}$ medida do campo, os dois eletrodos são movidos de ponto a ponto. 


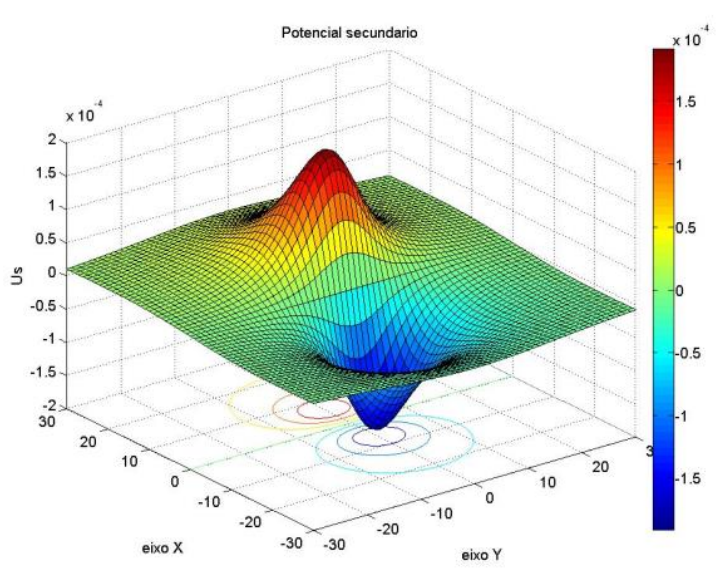

Potencial elétrico secundário

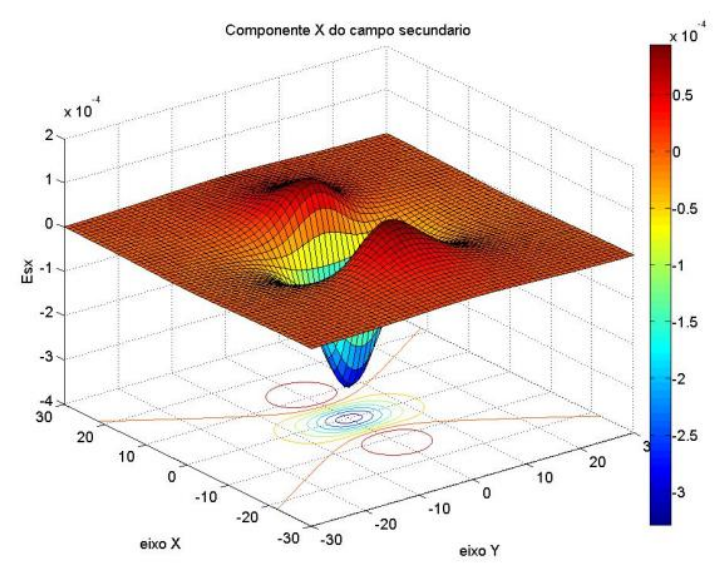

Campo elétrico horizontal secundário

\section{Discussão e Conclusões}

As figuras mostram com clareza a posição e a extensão horizontal aproximada do bloco. As amplitudes, do potencial e do campo, dependem do contraste de resistividade, entre o bloco e o meio, e da profundidade do bloco. A estimativa dessas grandezas requer familiaridade com o resultado de vários modelos onde esses parâmetros sejam variados.

Este é apenas o trabalho inicial; muitos outros são necessários para que esse método se torne operacional. O ideal é que se adapte os métodos existentes de medida de campo elétrico no ar, usados em meteorologia e na proteção contra descargas elétricas, para os campos fracos da geofísica. O uso desses campos tornará os levantamentos mais simples, rápidos e baratos.

Medidas simultâneas do potencial, do campo elétrico e do campo magnético, permitirão uma interpretação mais segura porque enquanto potencial e campo elétrico trazem informações das superfícies, onde as cargas ficam depositadas, o campo magnético traz informações sobre o volume, onde as correntes fluem.

Trata-se de um projeto promissor que necessita de trabalhos futuros.

\section{Agradecimentos}

Agradeço aos membros da banca examinadora da minha tese de doutorado submetida ao CPGG/UFBA.

Banca Examinadora:

Dr. Olivar Antônio Lima de Lima (UFBA, orientador)

Dr. Hédison Kiuity Sato (UFBA)

Dr. Carlos Alberto Dias (UENF)

Dr. Cícero Roberto Teixeira Régis (UFPA)

Dr. Luiz Gallisa Guimarães (UFRJ)

\section{Referência}

TESE DE DOUTORADO EM GEOFÍSICA

O Método da Eletrorresistividade a partir das Cargas Elétricas com Modelagem Tridimensional Sérgio Cavalcante Guerreiro CPGG/IGEO/UFBA - 22/08/2014 